\title{
Pulmonary empyema in a patient with schizophrenia and poor dentition
}

\author{
Hongru Ren MD, Andrew Walkty MD, Biniam Kidane MD MSc
}

\author{
— Cite as: CMAJ 2021 November 8;193:E1695. doi: 10.1503/cmaj.202556
}

A 55-year-old man with a medical history of schizophrenia and a seizure disorder presented to our hospital with subacute onset of cough, weight loss and confusion. When we examined him, he appeared cachexic, and was disoriented and afebrile but hemodynamically stable. We noted multiple dental caries. Chest radiography and computed tomography showed that he had left lower lobe consolidation with a loculated pleural effusion (Figure 1A). Pleural fluid analysis was consistent with the diagnosis of empyema (turbid colour, protein $42 \mathrm{~g} / \mathrm{L}$, pleural fluid to serum protein ratio 0.8 , lactate dehydrogenase $958 \mathrm{U} / \mathrm{L}$, pleural fluid to serum lactate dehydrogenase ratio 5.5).

Gram stain of a pleural fluid sample obtained after 3 days of antimicrobial therapy revealed Gram-negative bacilli. No pathogens were grown on aerobic culture of the pleural fluid, but Slackia exigua (a Grampositive bacillus) was isolated on anaerobic culture (Appendix 1, available at www.cmaj.ca/lookup/doi/10.1503/cmaj.202556/tab -related-content). Given the different results on Gram stain and culture of the pleural fluid, we diagnosed a polymicrobial infection likely caused by aspiration.

We administered intrapleural fibrinolytic therapy via pigtail catheter to facilitate drainage of the empyema (Figure 1B). The patient completed a 3-week course of oral amoxicillin-clavulanate, recovered and went on to receive definitive dental treatment after concerted advocacy work over many months by our team, in collaboration with his social worker, group home, public guardian and trustee, and outpatient dentistry services.

Empyema may occur after aspiration. Risk factors for aspiration and subsequent empyema in our patient included poor dentition, antipsychotic medication use, and a history of seizures. S. exigua is a non-spore-forming, anaerobic bacillus that is part of the human oral microbiota. ${ }^{1}$ It is most commonly associated with dental infections, but has occasionally been isolated on culture from patients with extraoral infections such as empyema and lung abscess, meningitis, cavernous sinus thrombosis and intra-abdominal abscess. ${ }^{2}$ Infections with S. exigua tend to be polymicrobial, as we speculate was the case in our patient. Our patient's mental illness and socioeconomic situation were barriers to obtaining preventive dental treatment. This case underscores the importance of poor dental health and aspiration in the pathogenesis of lung infections.

\section{References}

1. Wade WG, Downes J, Dymock D, et al. The family Coriobacteriaceae: reclassification of Eubacterium exiguum (Poco et al. 1996) and Peptostreptococcus heliotrinreducens (Lanigan 1976) as Slackia exigua gen. nov., comb. nov. and Slackia heliotrinireducens gen. nov., comb. nov., and Eubacterium lentum (Prevot 1938) as Eggerthella lenta gen. nov., comb. nov. Int J Syst Bacteriol 1999;49:595-600.

2. Kawasuji H, Kaya H, Kawamura T, et al. Bacteremia caused by Slackia exigua: a report of two cases and literature review. J Infect Chemother 2020;26:119-23.

\section{Competing interests: None declared.}

This article has been peer reviewed.

The authors have obtained patient consent.

Affiliations: Departments of Internal Medicine (Ren) and Medical Microbiology and Infectious Diseases (Walkty), Max Rady College of Medicine, University of Manitoba; Shared Health (Walkty); Section of Thoracic Surgery (Kidane), Department of Surgery, Rady Faculty of Health Sciences and Department of Community Health Sciences (Kidane), University of Manitoba; Cancer Care Manitoba Research Institute (Kidane), Winnipeg, Man.

Content licence: This is an Open Access article distributed in accordance with the terms of the Creative Commons Attribution (CC BY-NCND 4.0) licence, which permits use, distribution and reproduction in any medium, provided that the original publication is properly cited, the use is noncommercial (i.e., research or educational use), and no modifications or adaptations are made. See: https://creativecommons.org/ licenses/by-nc-nd/4.0/

Correspondence to: Biniam Kidane, bkidane@hsc.mb.ca 